\title{
Missing Early Education and Care During the Pandemic: The Socio-Emotional Impact of the COVID-19 Crisis on Young Children
}

\author{
Suzanne M. Egan ${ }^{1}$ (D) Jennifer Pope ${ }^{2} \cdot$ Mary Moloney $^{2} \cdot$ Clara Hoyne $^{1} \cdot$ Chloé Beatty $^{1}$
}

Accepted: 13 April 2021 / Published online: 27 April 2021

(c) The Author(s), under exclusive licence to Springer Nature B.V. 2021

\begin{abstract}
Worldwide, millions of children have missed out on early childhood education and care (ECEC) due to the closure of their settings during the COVID-19 pandemic. However, little is known about the socio-emotional impact of these closures on young children. This paper draws upon a study of 506 parents of children aged 1-10 years in Ireland who completed the online Play and Learning in the Early Years (PLEY) Survey during lockdown in May and June 2020. Parents responded to a series of questions about their child's play, learning and development during lockdown, and described the impact of the restrictions on their children's lives. The study was approved by the institutional ethics committee. Findings indicate that most children missed their friends, playing with other children, and the routine and structure of ECEC and school settings. Parents described the negative impact of the closure of these settings on their children's social and emotional well-being, which they suggested, resulted in tantrums, anxiety, clinginess, boredom, and under-stimulation. However, some parents did report positive aspects of lockdown for their children and the family, including more time to play with siblings and a break from the usual routine. While the findings of the PLEY study indicate that children's socio-emotional development was severely disrupted during lockdown, with a variety of negative impacts, this experience was not universal. Moreover, the findings suggest that families missed the nurturing environment provided by ECEC programs that supported their children's socio-emotional development, as well as the structure and routine afforded by their children's participation in early childhood programs.
\end{abstract}

Keywords COVID-19 · Socio-emotional development $\cdot$ School $\cdot$ Education $\cdot$ Early childhood education and care

\section{Introduction}

The global COVID-19 pandemic has had a huge impact on the world (e.g., Prime et al., 2020). Indeed, many countries around the world took unprecedented steps to prevent and contain spread of the virus. UNICEF (2020) for instance, reported that physical distancing, shutting down of nonessential businesses, and suspension of community and recreation services and programmes took place in most countries. In addition, most countries also closed schools and early childhood education and care (ECEC) settings,

Suzanne M. Egan

Suzanne.Egan@mic.ul.ie

1 Department of Psychology, Mary Immaculate College, University of Limerick, Limerick, Ireland

2 Department of Reflective Pedagogy \& Early Childhood Studies, Mary Immaculate College, University of Limerick, Limerick, Ireland playgrounds, businesses, restaurants, and recreational centres. Globally, the numbers of children affected by school closures alone was staggering, ranging between 1.4 billion children (Roberton, 2020) and 1.6 billion children in 190 countries (i.e., approximately $90 \%$ of the world's school age children) (UNESCO, 2020). Indeed, the United Nations (UN, 2020) noted that while children were not the face of the pandemic, they risked being among its biggest victims in terms of the potential profound effects on their wellbeing.

Much research to date has necessarily focused on the medical and physical health impacts of the coronavirus on adults and children. While previous research offers some general insights into the likely psychological impact of the restrictions on children, the nature of previous research, and the scale, extent, and length of the COVID-19 crisis, make it difficult to draw specific conclusions about effects of the pandemic on young children. Many researchers (e.g., Brooks et al., 2020; Loades et al., 2020; Orben et al., 2020; Townsend et al., 2020) have highlighted that the crisis and 
restrictions are likely to have negative psychological effects on children (Loades et al., 2020), adolescents (Orben et al., 2020), and parents.

For example, a recent rapid review (Brooks et al., 2020) examining evidence relating to the impact of quarantine and social isolation on psychological well-being and mental health in children, found mainly negative effects. However, none of the papers included in the review focused on young children. Another rapid review (Loades et al., 2020) highlighted the negative psychological impact of loneliness and social isolation on healthy children and adolescents. However, the majority of the papers in this review related to children aged over 10, with none including children aged under 5 years. Prime et al. (2020) note the high levels of anxiety and stress reported by families in Canada, and based on previous literature on adversity (such as natural disasters, war and economic upheaval), maintain that the consequences of these experiences may be longstanding. The impact on children's well-being when faced with such adversity depends largely on family relationships (e.g., Prime et al., 2020).

Given the unprecedented nature of the COVID-19 pandemic and widespread lockdown, it is important to gather empirical evidence relating to the potential psychological effects of the current crisis on very young children and their families. Published empirical research of the effects on families is just beginning to emerge (e.g., Brom, et al., 2020; Spinelli, et al., 2020). For example, Spinelli et al. (2020) reported findings from data gathered during lockdown in Italy from parents, and found that parental stress and perceptions of quarantine were associated with children's behavioural and emotional problems. Surveys by Save the Children (2020a) of over 6000 children and parents in the US, Germany, Finland, Spain, and the UK also suggest that many children struggled with boredom and feelings of isolation. The aim of the current study was to examine the evidence relating to the socio-emotional effects of the pandemic, gathered during a period of lockdown in Ireland, and to consider the impact of the closure of schools and ECEC settings on young children.

\section{Socio-Emotional Development and Early Childhood Education and Care}

Although socio-emotional development is defined in different ways, in general, it refers to the process through which children develop the ability to initiate and maintain trusting relationships with adults and peers; to understand and express emotions in appropriate ways; and to become independent, explore and engage with the environment and make responsible decisions (Ashdown \& Bernard, 2012). In short, socio-emotional development is concerned with how children think, feel, and act. As noted by Berk et al.
(2006, p. 74), "the early childhood years are a crucial time for the development of self-regulation - an array of complex mental capacities that includes impulse and emotion control, self-guidance of thought and behaviour, planning, self-reliance, and socially responsible behaviour" (p. 74). Furthermore, Kostelnik et al. (2015) assert that children's social and emotional development affects their overall development and learning.

Ashdown and Bernard (2012) associate socio-emotional development with five core competencies: self-awareness, social awareness, self-management, relationship skills, and responsible decision-making. Moreover, social and emotional skills include self-confidence, empathy, concentration, persistence, attentiveness, effective communication, and problem-solving (Santos et al., 2012). All of these skills enable children to interact positively with others, have a positive attitude toward school, and have increased academic performance (Ho \& Funk, 2018). According to Domitrovich et al. (2017) children with poor socio-emotional competence display more challenging behaviours, including aggression, delinquency, and substance abuse.

Children learn about emotions and how they can be managed in the context of social interactions. While such learning begins in the home, high quality Early Childhood Education and Care settings are also considered to be an important locus for supporting children's social-emotional development (e.g., Blewitt et al., 2020; Vandenbroeck et al., 2018). Early childhood educators can promote social and emotional skills in the classroom by providing children with a safe, nurturing, and predictable environment (National Council for Curriculum and Assessment (NCCA), 2009; Ho \& Funk, 2018). In a nationally representative longitudinal study, parents of young children in Ireland rated children who attended centre-based care as having fewer emotional and peer problems (Russell et al., 2016) and further analysis observed that non-parental childcare of any type at nine months was found to have a small positive effect on socioemotional outcomes at age five. Teachers, educators, and caregivers play key roles in helping children develop social and emotional competence (Kostelnik et al., 2015). ECEC settings are especially rich in opportunities that support children to build and consolidate socio-emotional skills.

Play-based learning is particularly relevant for young children, providing them with relevant and meaningful learning opportunities (NCCA, 2009; UNICEF, 2020) through which they learn to cooperate and display socially appropriate behaviour. UNICEF (2020) posits that "play sets the foundation for the development of critical social and emotional knowledge and skills. Through play, children learn to forge connections with others, and to share, negotiate and resolve conflicts, as well as learn self-advocacy skills. Play also teaches children leadership as well as group skills" (p. 10). In addition, children use play as a tool to 
build resilience and coping skills, "as they learn to navigate relationships and deal with social challenges" (p. 10). It is widely acknowledged that this increased social competence is associated with more considerate behaviour, friendliness, conflict resolution, and peer acceptance (e.g., Elias \& Berk, 2002; Singer \& Singer, 2004).

As indicated, ECEC results in many benefits for young children's learning and development, and in particular, it supports their emerging socio-emotional development. From a bio-ecological perspective (Bronfenbrenner \& Morris, 2006) schools and ECEC facilities are important settings in which children develop physically and psychologically. These settings interact with the microsystem of the home environment to support children's development. Many other individual factors also affect young children's socioemotional development. For example, Russell et al., (2016) identified children's health, gender, and a range of family and socioeconomic factors as having an impact on young children's socio-emotional development also. The current research focuses on wider factors that may have affected socio-emotional development, namely the COVID-19 crisis, which affected children and families on a global scale.

As mentioned earlier, millions of children have missed out on ECEC due to the closure of their settings during the COVID-19 pandemic. In the case of Ireland, these facilities closed with one day's notice in March 2020 and continued to be closed for months, causing major disruptions for children and parents. Little is known about how these closures affected children and families during this time. As the lockdown was an unprecedented experience, investigating the experiences of families and gaining parental insights into the impact of the closures on their young children was deemed valuable. This paper draws upon data gathered online from parents during the initial period of lockdown in Ireland, and provides insights into the socio-emotional impact of the COVID-19 crisis on young children.

\section{Method}

This section describes how the study was undertaken, providing details of the online parental-report Play and Learning in the Early Years (PLEY) Survey. The survey consisted of three sections and asked a wide range of questions about children's play, learning, and development, including questions related to children missing ECEC, school and other children, which are the focus of this paper, and described in more detail below. Many questions on the survey were drawn directly from the longitudinal Growing Up in Ireland Study (McCrory et al., 2013; Williams et al., 2019), adapted from previous research, or developed specifically for the PLEY Survey (e.g., questions relating to the impact of the COVID-19 restrictions). The survey was open to participants for two weeks from May 21 through June 3, 2020.
At this time in Ireland, early childhood education and care settings and schools had been closed since March 13th, with the announcement of these closures made by the government on March 12th.

Additional national restrictions were put in place in Ireland on March $27^{\text {th }}$, when the Irish government directed that all citizens must stay at home except in specific circumstances (e.g., travel to and from essential work, shop for food and, attend medical appointments) and practice social distancing (i.e., remain $2 \mathrm{~m}$ apart in all public spaces). Adults and children could leave their home for brief physical exercise, but only within $2 \mathrm{~km}$ of their home (RTE News, 2020 (Ireland's National Public Service Media)). This limit was extended to $5 \mathrm{~km}$ on May 1 st and to $20 \mathrm{~km}$ on June 8th. A Road Map for Reopening Ireland, published on May 18th, which proposed a phased re-opening of the country up to August, 2020 (Government of Ireland, 2020), with some ECEC settings reopening June 29th, and schools planning to reopen in late August or early September 2020 (the typical reopening period in Ireland after summer holidays).

\section{Materials}

The first section of the survey, with which this paper is concerned, explored the impact of the COVID-19 restrictions on children's play, learning and activities (e.g., amount of time per day spent on screens or in outdoor play). Parents were also presented with a series of statements relating to the impact of the restrictions on their child and asked to rate their agreement with each statement on a 5 point Likert scale $(1=$ strongly disagree, $5=$ strongly agree). The following four statements related to their child missing ECEC, school, and friends: (1) My child misses childcare, (2) My child misses school, (3) My child misses friends, and (4) My child misses playing with other children. In addition to the quantitative data collected, the survey instrument included an open-ended question which allowed parents to provide information in response to a question asking them to describe the biggest change to their child's play or activities as a result of the COVID-19 crisis. These responses were important in gaining deeper insights into what Marshall and Rossman (2006) refer to as the individual lived experiences of study participants during this unprecedented 'lockdown' time.

\section{Procedure}

Parents with young children were recruited through newspaper advertisements and also through social media platforms, including Twitter and Facebook. Information about the study was shared with schools, parenting networks, early years' organisations and centres, and parents of young children 
Table 1 Descriptive statistics for quantitative variables

\begin{tabular}{|c|c|c|c|c|c|c|}
\hline Survey item & $\begin{array}{l}\text { Percentage of par- } \\
\text { ents agreeing }(\%)\end{array}$ & Mean (SD) total & Mean (SD) girls & Mean (SD) boys & $\begin{array}{l}\text { Mean }(\mathrm{SD}) \text { age } \\
1-5 \text { years }\end{array}$ & $\begin{array}{l}\text { Mean } \\
\text { (SD) age } \\
6-10 \text { years }\end{array}$ \\
\hline Misses friends & 90 & $4.46(0.88)$ & $4.54(0.87)$ & $4.39(0.87)$ & $4.26(.99)$ & $4.58(0.76)$ \\
\hline $\begin{array}{l}\text { Misses playing with } \\
\text { other children }\end{array}$ & 87 & $4.42(0.99)$ & $4.46(1.00)$ & $4.38(.98)$ & $4.32(1.08)$ & $4.48(0.93)$ \\
\hline Misses school & 81 & $4.16(1.12)$ & $4.31(0.98)$ & 3.99 (1.23) & $4.09(1.14)$ & $4.19(1.08)$ \\
\hline Misses childcare & 55 & $3.41(1.32)$ & $3.44(1.34)$ & $3.40(1.30)$ & $3.80(1.19)$ & $3.11(1.34)$ \\
\hline
\end{tabular}

who are active on social media. Those parents in turn shared this information with their contact networks by retweeting, posting, or forwarding information. Information about the survey and a link to it was also available on the Government of Ireland Parent's Centre (2020) webpage while the survey was open, and it was also shared on social media by the Government of Ireland's Department of Children and Youth Affairs (DCYA).

Participants completed the online survey via Qualtrics ${ }^{\mathrm{TM}}$ software (Qualtrics, 2019), after expressing initial interest in the survey by clicking on the advertised link. Prior to giving their informed consent to participate, participants were provided with detailed information about the survey and what was involved in completing it. Parents completed most of the demographic questions first, followed by the questions about the impact of COVID-19 on play, learning, and development, in the three sections of the survey. The study, which was granted ethical approval by the institutional ethics board, took approximately $20 \mathrm{~min}$ to complete.

\section{Participants}

The participants were recruited using non-probability convenience sampling. The final sample consisted of 506 participants ${ }^{1}$ (92.9\% mothers, $5.9 \%$ fathers, $1.2 \%$ other; Mean Age $=40.36$ years; $S D=4.81$ ). The participants' children ranged in age between 1 year and 3 months and 10 years and 11 months (49.6\% female, $49.8 \%$ male, $0.6 \%$ unspecified; $82.8 \%$ had siblings, and $71.3 \%$ were breastfed). The

\footnotetext{
${ }^{1}$ An additional 47 participants completed the initial demographic questions, but did not respond to any other parts of the survey and it was therefore not possible to include them in further analyses. Another 11 participants also had children aged outside the target age range of birth to 10 years old, and were therefore excluded from further analyses. The final sample of 506 participants was compared with those who just completed the demographic section to investigate whether they differed in terms of parent gender or age, or child gender or age, presence of siblings or breastfeeding. Of these variables, the age of the parent was the only variable that significantly predicted the participants' rate of completion. Participants were more likely to complete the survey if they were over 37 years of age.
}

mean age of the children was 6.41 years $(S D=2.44)$. However, for the purpose of this paper, from an early childhood perspective, the findings will mainly focus more specifically on children aged 8 and under $(\mathrm{n}=382)$.

The majority of participants were from Ireland (95.8\%), with the remaining participants from the United Kingdom $(2 \%)$, other parts of the world $(1.2 \%)$, or did not identify where they were from (1\%). Most parents had a third level/ university education (84\%) and indicated that they were working (61.1\% fulltime; $22.1 \%$ part time), while most of the remainder indicated they were on leave or looking after family (14.7\%). However, the majority of participants $(85.7 \%)$ also indicated that their work situation had changed because of the COVID-19 crisis, with $71.7 \%$ working from home, and $11.8 \%$ temporarily not working (furloughed) due to business closure because of the COVID-19 restrictions.

\section{Results}

Both the quantitative and qualitative data indicated that young children were missing many aspects of their lives during lockdown, including their ECEC setting, their school, their friends and playing with other children (see Table 1). The majority of parents (90\%) agreed that their child missed their friends. Additional analyses indicated the gender and age of the children affected some aspects of missing out. For example, girls had higher scores than boys for missing school, $\mathrm{U}=15,894, \mathrm{~N}=385, p=0.014$, and for missing their friends, $\mathrm{U}=26,986, \mathrm{~N}=501, p=0.003$. There were no significant gender differences for missing playing with other children, $\mathrm{U}=29,155, \mathrm{~N}=503, p=0.123$, or for missing childcare, $\mathrm{U}=9959, \mathrm{~N}=287, p=0.701$. Younger children (aged 1-5 years) had significantly higher scores for missing ECEC than children aged 6 and over, $U=6850$, $\mathrm{N}=283, p<0.001$, although they had lower scores for missing friends, $\mathrm{U}=23,339, \mathrm{~N}=493, p<0.001$. The quantitative data were also analysed to compare the responses for children that had siblings to those that were an only child, but no significant differences in responses were found between the two groups, all $p$ 's $>0.05$. 
The qualitative data were analysed through a process of thematic analysis. Given that these data were exploring a new phenomenon, predetermined themes were not identified. Instead, the data were analysed to gain the perspectives or multiple realities of the parents in this study (Braun \& Clarke, 2006, 2013). Through the thematic analysis process, key themes were identified by the researchers. Two researchers individually immersed themselves in the qualitative responses from parents. Each response was treated as a unit of analysis. Through an iterative process of reading and rereading responses, the coders identified key themes and sub-themes, independently of each other. There was a high level of inter-rater reliability between the two coders, prior to discussing the themes that emerged. Examples of each theme and sub-theme were reviewed and considered.

Theme saturation was achieved through reading and rereading, and full agreement was reached through discussion. Both coders determined and agreed which parts of the data were key representations of the identified themes and these are presented below. These themes included: 'missing' from a structural perspective (early childhood education and school, activities, structure, routine) and 'missing' from a relational perspective, as a lack of interaction was another key theme. Another key theme to emerge from the data related to the socio-emotional impact that the lockdown had on children and their parents, with both negative and positive effects noted by parents.

From a structural perspective, many parents mentioned how the children missed the routine and structure provided by the early childhood or school setting. Noting that her 3 -year-old daughter "has gone to the childcare setting since she was 6 months", one parent articulated how her little girl "strongly misses the social aspect of it, the routine and all the activity". Although this parent had provided "paint, playdough etc.", and they "make things together at home", her daughter "has said she has more fun painting and creating with her friends. She is very sociable". Another parent stated that her 7-year-old daughter "definitely misses her school friends and the routine of school". Another noted her 5-year-old son was "[n]ot going out as much, usually he loved going to school as he needs routine".

From a relational perspective, a lack of interaction prominently emerged across the qualitative data, with terms such as 'lonesomeness', 'alone', 'isolation', and lack of 'interaction' featuring regularly. One parent noted the difficulties for her 2-year-old daughter, and for herself. As indicated in the following commentary, these difficulties ranged from lack of family support and friends to overall absence of routine and structure for her daughter, "Not having other children (friends or cousins) to play with, which is especially challenging as I also have a baby who was just 7 weeks old when lockdown began. I'm breastfeeding him and have no family support during the day so my attention is torn between the two. She finds this very difficult. She misses her classes (Sensory Play class and gymnastics) and regular playdates (would have been probably twice a week on average) as well as all of the activities she would have been doing at crèche".

This sense of missing out on activities and on interaction with other children was also reported by parents in relation to their school-going children. One parent noted in relation to their 4-year-old son that "The biggest change has been having no school and friends around to play with or come over to our house". This parent described the effect upon her son, describing how he repeatedly questioned returning to school, having friends to his house to play and when the virus would finish. In the words of the parent, he "is constantly asking when he can go back to school. When can he have friends over to play? When will the virus be over? $\mathrm{He}$ absolutely loves school and learning and I do worry about when he goes back, if things are crazy different it could put him off."

The relationship between children missing ECEC, school, their friends, and/or the routine provided by their setting, and the socio-emotional and behavioural effects of missing out on these aspects of their lives was evident across the qualitative responses. Parental concerns about their child's social-emotional behaviour were noted in many of the responses. One parent whose 2-year-old daughter "was attending crèche" described her as "very out-going and loved seeing her friends" prior to lockdown. As a result of lockdown however, her daughter "has become very very attached to mum and is cautious at first when she sees some one out of the family home. Before the virus she used to be so outgoing." A parent of a 3-year-old girl said she was "more subdued and wants to go to bed more often". Another parent of a 3-year-old boy described him as "very spaced out, not the same child at all", while a parent of a 4-year-old boy stated "he's sad and less willing to share". Commenting on their 5 -year-old son, another parent noted that while "they play more at home as they aren't in playschool...emotionally [he is] a lot more demanding and his behaviours have reverted to that of a younger child". This parent also alluded to how the closure of external services also affected the child, who "had speech issues which had much improved after speech therapy". During the lockdown however, the child's speech "has also regressed."

These emotional and behavioural effects were also present in older children missing out on school, with one parent stating that her 7-year-old child was "Missing friends and school so tantrums are regular and bedtime is disrupted", while another parent described her 7-year-old son as suffering from "[i] solation and anxiety. He misses the routine of school. He misses meeting his friends". A parent of 6-yearold noted that "behavioural issues are magnified" while a parent of a 7-year-old girl mentioned her daughter's "[1]ack of energy, all the down time has brought her interest and 
mood down". Another parent of an 8-year-old boy said "He has become very moody and lazy".

In addition to the impact on children, parents' responses pointed to how the closure of ECEC and school settings affected parents' own socio-emotional states. The difficulties in working from home while simultaneously providing care for their child were often noted. One parent, for example, noted that her 2-year-old son was "A bit more clingy to me and wanting me to be involved in the play especially at times I'm trying to balance working from home while providing care to him and his older sister". Another parent of a 3-year-old stated that "Being taken from friends in crèche/ playschool and staying away from cousins has been very difficult". For this parent, the fact that both parents were "working full time from home has been extremely hard and challenging with child constantly asking to be played with and not understanding the demands and stress of work. It is truly a desperate situation and I feel the pressure on working parents and impact on kids has been downplayed and not sufficiently acknowledged".

Parents also highlighted how screens were being used as a 'digital babysitter' to replace the care and education usually provided in an ECEC setting. One parent of a 2-yearold stated, "We are working at home so we can't dedicate $100 \%$ of our time to her so she ends up watching a lot of TV. She used to go to crèche, so this was not a usual situation", while another said "She is in front of the TV for 5-6 h per day because I have to work. Before this she was in crèche with 9 other children". Although this parent of a 2-yearold girl takes "occasional short breaks to play" with her daughter, she claims that "she often looks bored and under stimulated". Some parents also felt "horrible" about using screens to keep their child occupied. For example, a parent of a 1-year-old stated, "We need to use the TV as entertainment while we work so he watches far more TV than we are comfortable with. And he does everything glued to the TV now which is a horrible feeling as a parent", while the parent of a 2-year-old noted, "Because both parents have to work from home her screen time had increased from about $1 \mathrm{~h} \mathrm{a}$ day to (god this hurts to say) about $4 \mathrm{~h}$ a day".

While most parents commented on the negative effects of the lack of early education and care, several respondents commented on the positive impact of lockdown on young children and families. As such, these parents identified positive relationships among siblings and the lack of routine and structure as being particularly positive, with one parent of a 5-year-old, describing lockdown as "a break from the daily grind". A parent of a 1-year-old noted that their son had "[m]ore outdoor play as he has more freedom at home than at childminders", while another said her 3 year old had "[m] ore time to play at home, not having to run and race places and not being in crèche".
This was also evident with older children. For instance, a parent of a 6-year-old stated her child had "[m]ore time to play with toys and play outside now compared to school/ activities pre Covid". Likewise, the parent of an 8-year-old noted their child had "[m]ore freedom- being allowed to just be. We have not placed a huge emphasis on structured learning allowing them to explore for themselves". One parent also noted benefits for their 4-year-old's child's language: "Lots of one-to-one time with parents and his younger sister at home. His language has improved noticeably, he has had no ill-health whatsoever and he has loads of adventures and treasure hunts/picnics in a local forest/hillfort".

\section{Discussion}

The findings of this study provide empirical evidence of the socio-emotional impact of the COVID-19 crisis on young children, demonstrating both positive and negative effects. Triangulation of the findings from the quantitative and qualitative data provided by parents suggested that most children were 'missing' their ECEC settings and schools. Findings from the qualitative parental responses for children indicates that children missed the routine, structure and activities provided by these early childhood settings and schools. As reported, parents also indicated that their children experienced a lack of interaction and missed peer relationships with friends and other children in the early childhood setting or school.

These findings are consistent with the results of a global Save the Children survey, in which parents described how more than half of the children surveyed (56\%) who were not in contact with their friends, reported that they were less happy and more worried than before (Save the Children, 2020a). When children play freely with other children, they cooperate and learn to work together (Howard \& McInnes, 2013; Singer et al., 2006) and they get to both express and listen to the opinions and ideas of their peers (Fantuzzo et al., 1998). Interaction with other children supports many aspects of socio-emotional development, and the imposed restrictions severely disrupted these opportunities for interaction.

Parents also had concerns for their child's socio-emotional development now and in the future, with some parents describing anxiety, clinginess, isolation and low mood. These findings are consistent with the findings of further surveys conducted by Save the Children in the US and Europe. The results of these surveys indicated that children reported feeling "anxious, bored and fearful". Half of children interviewed in the US were worried, while a third felt scared, and a quarter of the children reported feeling anxious (Save the Children, 2020b). The findings from the current study, and from others internationally, suggest that some 
young children may need additional support in overcoming some of the negative impacts of the COVID-19 crisis on their socio-emotional development. The findings from the quantitative data also indicate that certain individual factors such as the gender or age of the child may also be important in considering how the child was affected, and potentially what additional supports may be needed.

Supporting consistent relationships is a key indicator of quality in early childhood education and care settings and is highlighted in Irish policy and legislation. In the guidelines for reopening of early childhood education and care settings in June 2020, the Irish government stressed the importance of a child-centred approach, effective communication with parents, and the use of play pods (Department of Children and Youth Affairs (DCYA), 2020). The play pod model restricts interactions between closed groups of children and adults as an alternative to social distancing, which is not possible with young children. As such, play pods facilitate infection control by reducing excess contacts but also help to maintain effective relationships. According to the DCYA (2020, p. 2), "'Play-pods' develop a cohesive, consistent group of children who feel safe". The 'pod' system was also implemented in Irish schools both to keep the number of interactions to a reasonable number in an indoor setting, while also helping to support relationships after almost six months of school and ECEC closures. This national policy for the reopening of these care and education settings highlights the importance of wider macrosystem influences (Bronfenbrenner \& Morris, 2006) on supporting child development as restrictions ease around the world.

While the findings show the varied negative impacts on young children, the current study also indicates the impact of the closure of schools and ECEC settings on parents as well. Some parents made reference to their own emotional state and the challenges of balancing work and home life during this period of lockdown. The majority of respondents in this study were mothers and the findings are consistent with those of Lagomarsino et al. (2020) who reported that Italian mothers had similar difficulties in reconciling work commitments, family, and domestic duties, particularly with children aged from birth to six. There appear to be greater impacts for mothers than fathers in terms of balancing work, domestic and caring responsibilities (Lagomarsino et al., 2020) and this has highlighted gender inequalities in division of labour within the home in Italy (Balenzano et al., 2020). Furthermore, Balenzano et al. (2020) found that the experience of lockdown and working from home was stressful for many parents.

These findings are consistent with previous research which shows that social factors have a role to play in psychological development and family functioning. For example, Belsky (1984) proposes that the social environment and social support influence the parent-child relationship. Parent characteristics such as mental health, anxiety, or depression, and a child's own characteristics are important too. For example, Giallo et al. (2013) found that parents had less parental involvement when they had health issues, were in high distress, lacked social support, had troubled relationships, or when their child had a difficult temperament. Any or a combination of these factors, such as those reported by parents in the current study, could limit parental interactions and involvement in supporting their child's play, learning, and development as they strive to meet the child's basic care needs, particularly while also juggling working from home. The COVID-19 crisis and resulting lockdown had a significant impact on the social environment of families and the typical supports available to parents to care for their children (Spinelli et al., 2020), emphasising the importance of wider societal and cultural influences on children's socioemotional development (Bronfenbrenner \& Morris, 2006).

However, our findings suggest that some parents viewed the lockdown period, and the associated lack of structure or routine, as having a positive effect in terms of the child's socio-emotional development. They noted the increased opportunities and time to play with siblings, to play alone, and to play outdoors. It may be the case that some of the parents that reported positive experiences had settled into a new routine after two months of lockdown and their young child had adapted well to the change in circumstances and lack of early childhood care or education. Balenzano et al. (2020) also observed some Italian families reported positive outcomes in terms of cohesion that resulted from spending increased time together indoors. These families demonstrated resilience and the capacity to cope with family stress and adjust to lifestyle changes.

\section{Implications of the Findings}

Prime et al. (2020) in their conceptual framework for resilience and well-being highlighted the importance of family processes which may act as a buffer against the emotional impact of COVID-19, as well as promoting resilience through close relationships and shared family beliefs. The findings from the current study highlight the non-homogenous nature of the experiences of families and how they were impacted by lockdown. As governments globally provide additional supports for children, parents, and families to support the socio-emotional development and mental health of children, it is important to consider individual differences in experiences, and the many other factors that influence perceptions of those experiences. We recommend that each child's unique experience of the pandemic be taken into account in tailoring supports to the areas in which they faced the greatest challenges (e.g., support for behavioural issues, language delays, social interactions). 
It is also important to consider the implications of the findings reported in this paper relating to how the COVID restrictions affected young children's social-emotional development in ECEC. In this regard, schools and early childhood settings can provide a secure safe base for young children, enabling them to re-establish relationships with their teachers and their peers. As the discourse of 'learning loss' gathers momentum, in the context of early childhood education specifically, teachers must prioritise children's mental health and social-emotional development through relational pedagogy. Opportunities for play are paramount so that young children can develop critical social and emotional skills, build resilience, and develop coping skills to deal with adverse situations (National Scientific Council on the Developing Child, 2015). The role and response of early childhood educators is, therefore, critical.

We recommend that early childhood teachers and policy makers embrace 'slow pedagogy' and 'slow knowledge', within a system which should be characterised by listening (Clark, 2020); the antithesis of the 'hurried child' (Elkind, 1987). We urge early childhood teachers to find the rhythm of the children they are working with, to listen deeply, observe deeply, and connect deeply with children. We recommend reading slowly; playing slowly, snacking slowly, and walking slowly as a means of facilitating the natural rhythms of the child's physiology. As noted by Clark (2020), slow has become the new urgent.

\section{Limitations, Strengths, and Future Research}

The findings from this study provide insights into the experiences of children and their parents during the initial COVID19 crisis lockdown in Ireland, when early childhood care and education settings were closed. However, it is important to note the limitations of the study when considering the findings, including the generalisability of the findings. For example, the sample is a volunteer sample of mainly welleducated and employed Irish parents. It may be the case that families with other characteristics, living in more challenging and adverse circumstances, or based in other countries, had quite different experiences of the period of lockdown. Additionally, different countries around the world implemented COVID-19 restrictions in different ways, in terms of the closure of schools, crèches, and workplaces, which may affect family experiences. For example, some countries had shorter periods of complete school closures (e.g., UK) or fewer restrictions on citizens (e.g., Sweden), while others had more restrictions (e.g., Spain, where children were not permitted to go outside their homes for approximately six weeks in March and April 2020).

Furthermore, future research should also explore the experiences of all family members directly. During lockdown it was not feasible to gather data in person, due to the restrictions in place. Mothers were the main respondents to the PLEY survey, and thus it is important that the perspectives of fathers, and of young children themselves, are ascertained in subsequent studies, and through multiple means, such as interviews and observations, as well as through surveys. However, a strength of the current study is that parents responded in real-time, while they were in lockdown, while future studies may have to rely on recall of the experience. The combination of both quantitative and qualitative data on this topic also provide rich insights into family experiences during this time. Future research might further explore children's experiences of missing ECEC, the socio-emotional impact of their return to ECEC, the impact of 'play pods,' and the perceptions of ECEC professionals regarding the effect of the lockdown and the restrictions on young children.

\section{Conclusion}

The changes parents described as a result of the COVID-19 lockdown are reflective of their own individual experiences but many commonalities were found in these experiences too, relating to the importance of schools and ECEC settings for young children and their families. These commonalities include children missing their activities, routines, and friends at school and childcare, as well as the parental stress of juggling working from home along with increased childcare and education responsibilities. The findings from the PLEY study give insights into the socio-emotional impact of the COVID-19 lockdown on young children and their parents, and provide a foundation for future research on this topic.

Funding This work was supported by a Mary Immaculate College Seed Funding Award granted to the first author (Grant Number SF201-7).

Data Availability Data is available on request from the corresponding author.

\section{Declarations}

Conflict of interest We declare no conflicts of interest.

Ethical Approval The research reported in the manuscript adhered to the ethical standards of the Psychological Society of Ireland (PSI) Code of Professional Ethics, (4.2.7; PSI, 2010), and ethical approval was granted (A19-027) by the Mary Immaculate College Research Ethics Committee. The procedures used in this study adhere to the tenets of the Declaration of Helsinki.

Informed Consent Informed consent was given by all individual participants included in the study. 
Consent to Publish Consent publish and present findings from the data in the study was given by all individual participants.

\section{References}

Ashdown, D. M., \& Bernard, M. E. (2012). Can explicit instruction in social and emotional learning skills benefit the social-emotional development, well-being, and academic achievement of young children? Early Childhood Education Journal, 39(6), 397-405. https://doi.org/10.1007/s10643-011-0481

Balenzano, C., Moro, G., \& Girardi, S. (2020). Families in the pandemic between challenges and opportunities: An empirical study of parents with preschool and school-age children. Italian Sociological Review, 10(3), 777-800. https://doi.org/10. 13136/isr.v10i3S.398

Belsky, J. (1984). The determinants of parenting: a process model. Child Development, 55(1), 83-96.https://doi.org/10.1111/j. 1467-8624.1984.tb00275.x

Berk, L. E., Mann, T. D., \& Ogan, A. T. (2006). Make-believer play: wellspring for development of self-regulation. In D. G. Singer, R. M. Golinkoff, \& K. Hirsh-Pasek (Eds.), Play = Learning: How play motivates and enhances children's cognitive and social-emotional growth.Oxford University Press.

Blewitt, C., Morris, H., Nolan, A., Jackson, K., Barrett, H., \& Skouteris, H. (2020). Strengthening the quality of educator-child interactions in early childhood education and care settings: A conceptual model to improve mental health outcomes for preschoolers. Early Child Development and Care, 190(7), 1-14. https://doi.org/10.1080/03004430.2018.1507028

Braun, V., \& Clarke, V. (2006). Using thematic analysis in psychology. Qualitative Research in Psychology, 3(2), 77-101. https:// doi.org/10.1191/1478088706qp063oa

Braun, V., \& Clarke, V. (2013). Successful qualitative research: A practical guide for beginners. SAGE.

Brom, C., Lukavsky, J., Greger, D., Hannemann, T., Strakova, J., \& Svaricek, R. (2020). Mandatory Home Education During the COVID-19 Lockdown in the Czech Republic: A Rapid Survey of 1st -9th Graders' Parents. Frontiers in Psychology, 5, 103. https://doi.org/10.3389/feduc.2020.00103

Bronfenbrenner, U., \& Morris, P. A. (2006). The bioecological model of human development. In R. M. Lerner \& W. Damon (Eds.), Handbook of child psychology: Theoretical models of human development. (pp. 793-828). John Wiley \& Sons.

Brooks, S. K., Webster, R. K., Smith, L. E., Woodland, L., Wessely, S., Greenberg, N., \& Rubin, G. J. (2020). The psychological impact of quarantine and how to reduce it: rapid review of the evidence. The Lancet, 395(10227), 912-920. https://doi.org/10. 1016/S0140-6736(20)30460-8

Clark, A. (2020). Towards a listening ECEC system. In C. Cameron \& P. Moss (Eds.), Transforming early childhood in England: Towards a democratic education. (pp. 134-150). UCL Press . https://doi.org/10.2307/j.ctv1503g6p.15

Department of Children and Youth Affairs. (2020). Preparing to reopen early learning and care and school-age childcare settings. Retrieved from https://first5.gov.ie/practitioners/reopening

Domitrovich, C. E., Durlak, J. A., Staley, K. C., \& Weissberg, R. P. (2017). Social-emotional competence: An essential factor for promoting positive adjustment and reducing risk in school children. Child Development, 88(2), 408-416. https://doi.org/ 10.1111/cdev.12739

Elias, C. L., \& Berk, L. E. (2002). Self-regulation in young children: Is there a role for sociodramatic play? Early Childhood Research Quarterly, 17(2), 216-238
Elkind, D. (1987). Early childhood education on its own terms. In S. L. Kagan \& E. F. Zigler (Eds.), Early schooling: The national debate. (pp. 98-115). Yale University Press.

Fantuzzo, J., Coolahan, K., Mendez, J., McDermott, P., \& SuttonSmith, B. (1998). Contextually-relevant validation of peer play constructs with African American Head Start children: Penn interactive peer play scale. Early Childhood Research Quarterly, 13(3), 411-431

Giallo, R., Treyvaud, K., Cooklin, A., \& Wade, C. (2013). Mothers' and fathers' involvement in home activities with their children: Psychosocial factors and the role of parental self-efficacy. Early Child Development and Care, 183(3-4), 343-359.

Government of Ireland. (2020). Roadmap for re-opening society and business. Retrieved from https://www.gov.ie/en/news/58bc $8 \mathrm{~b}-$ taoiseach-announces-roadmap-for-reopening-society-and-busin ess-and-u/

Ho, J., \& Funk, S. (2018). Preschool: Promoting young children's social and emotional health. Young Children, 73(1), 73-79

Howard, J., \& McInnes, K. (2013). The essence of play: A practice companion for professionals working with children and young people. Routledge.

Kostelnik, M. J., Soderman, A. K., Whiren, A. P., Rupiper, M. L., \& Gregory, K. M. (2015). Guiding children's social development and learning: Theory and skills. (8th ed.). Cengage.

Lagomarsino, F., Coppola, I., Parisi, R., \& Rania, N. (2020). Care tasks and new routines for Italian families during the COVID-19 pandemic: Perspectives from women. Italian Sociological Review, 10(3S), 847-868. https://doi.org/10.13136/isr.v10i3s.401

Loades, M. E., Chatburn, E., Higson-Sweeney, N., Reynolds, S., Shafran, R., Brigden, A., Linney, C., McManus, M. N., Borwick, C., \& Crawley, E. (2020). Rapid systematic review: The impact of social isolation and loneliness on the mental health of children and adolescents in the context of COVID-19. Journal of the American Academy of Child and Adolescent Psychiatry, 8567(20), 30337-30343

Marshall, C., \& Rossman, G. B. (2006). Designing qualitative research. (4th ed.). SAGE.

McCrory, C., Williams, J., Murray, A. Quail, A., \& Thornton, M. (2013)Growing up in Ireland: Design, instrumentation and procedures for the Infant Cohort at wave two (3 years) (Infant Technical Report No 3)Dublin:ESRI/TCD/DCYA

National Council for Curriculum and Assessment (NCCA). (2009). Aistear: The early childhood curriculum framework. Retrieved from https://ncca.ie/en/resources/aistear-the-early-childhood-curri culum-framework

National Scientific Council on the Developing Child. (2015). Supportive Relationships and Active Skill-Building Strengthen the Foundations of Resilience: Working Paper 13. Retrieved October 4, 2020, from http://www.developingchild.harvard.edu

Orben, A., Tomova, L., \& Blakemore, S. J. (2020). The effects of social deprivation on adolescent development and mental health. The Lancet Child \& Adolescent Health, 4, 634-640. https://doi.org/ 10.1016/S2352-4642(20)30186-3

Prime, H., Wade, M., \& Browne, D. T. (2020). Risk and resilience in family well-being during the COVID-19 pandemic. The American Psychologist, 75(5), 631-643. https://doi.org/10.1037/amp00 00660

Qualtrics (2019). Qualtrics Research Suite. Retrieved May 20, 2020, fromhttp://www.qualtrics.com

Roberton, T. (2020). Prioritising children's rights in the COVID-19 response (Editorial). The Lancet Child \& Adolescent Health, 4(7), 479

RTE (Raidió Teilifis Éireann) News. (2020). Timeline: Six Months of Covid-19. Retrieved September 1, 2020, fromhttps://www.rte.ie/ news/newslens/2020/0701/1150824-coronavirus/ 
Russell, H., Kenny, O., \& McGinnty, F. (2016). Childcare, early education and socio-emotional outcomes at age 5: Evidence from the Growing up in Ireland Study. ESRI.

Santos, R. M., Fettig, A., \& Shaffer, L. (2012). Helping families connect early literacy with social-emotional development. Young Children, 67(2), 88-96

Save the Children (2020a). Protect a generation. The impact of COVID19 on children's lives. Retrieved December 21, 2020, from https:// www.savethechildren.org.au/getmedia/c3cf8443-37bc-4420-b53bde6800d4dbaa/ProtectAGeneration_1189391475.pdf.aspx

Save the Children International. (2020b). "'Children at risk of lasting psychological distress from coronavirus lockdown': Save the Children." Save the Children International. Retrieved May 8, 2020, from https://www.savethechildren.net/news/\%E2\%80\%98childrenrisk-lasting-psychological-distress-coronavirus-lockdown\%E2\% 80\%99-save-children

Singer, D. G., \& Singer, J. L. (2004). Encouraging school readiness through guided pretend games. In: Zigler, E. F., Singer D. G., Bishop-Josef, S. J., (eds). Children's Play: The roots of reading. Zero to Three Press.

Singer, D. G., Golinkoff, R. M., \& Hirsh-Pasek, K. (Eds.). (2006). Play = learning: How play motivates and enhances children's cognitive and social-emotional growth. Oxford University Press. https://doi. org/10.1093/acprof:oso/9780195304381.001.0001

Spinelli, M., Lionetti, F., Pastore, M., \& Fasolo, M. (2020). Parents' Stress and Children's Psychological Problems in Families Facing the COVID-19 Outbreak in Italy. Frontiers in Psychology, 11, 1713. https://doi.org/10.3389/fpsyg.2020.01713

Townsend, E., Paton, D., Pitchford, N. et al. (2020). Every extra day of being stuck at home is harming children: Open Letter to Gavin
Williamson Secretary of State for Education Family Life in Lockdown 18 concerning the neglect of children and adolescents in government policy during the UK lockdown. The Sunday Times, June 14, 2020. Retrieved June 14, 2020, from https://www.theti mes.co.uk/article/letter-tothe-editor-school-shut-out-is-crushingchildren-nrkd5lgz7

United Nations (UN) International Children's Emergency Fund (2020). Covid-19 and children. UNICEF data hub. Retrieved from: https:// data.unicef.org/covid-19-and-children/

UNESCO (2020). Re-opening schools, when, where and how. Retrieved from https://en.unesco.org/news/reopening-schoo ls-when-where-and-how

UNICEF (2020). Early childhood development and Covid-19. Retrieved from https://data.unicef.org/topic/early-childhood-devel opment/covid-19/

Vandenbroeck, M., Lenaerts, K., \& Beblavý, M. (2018). Benefits of early childhood education and care and the conditions for obtaining them. European Expert Network on Economics of Education, $32,1-86$

Williams, J., Thornton, M. Murray, A. \& Quail, A. (2019). Growing Up in Ireland: Design, instrumentation and procedures for Cohort '08 at wave three (5 years). (Technical series No. 2019-2). Dublin: ESRI/TCD/DCYA

Publisher's Note Springer Nature remains neutral with regard to jurisdictional claims in published maps and institutional affiliations. 